\title{
Developing a tool to measure objectively the rib hump from an instantaneous 3D scanning in a full upright position. Results of 50 scoliosis before and after plaster cas
}

\author{
Jean Claude de Mauroy*, Julien David, Pascal Genevois, Frédéric Barral, Jean Jacques Lalain \\ From 7th International Conference on Conservative Management of Spinal Deformities \\ Montreal, Canada. 20-22 May 2010
}

\section{Introduction}

Comprehensive evaluation of the morphology of the spine and of the whole body is essential in order to correctly manage patients suffering from progressive idiopathic scoliosis. The Adams test implies a forward bending of the trunk and radiological examinations are performed in an upright position. The aim of this study is to explore the possibility to obtain a clinical measure of the rib hump in an upright position like the Cobb angle. Orten scanning system is a full 3D instantaneous measurement device in an upright position, working with structured light projection. Initially developed to avoid the plaster cast moulding, this system gives a full 3D digital representation of scoliosis. [1] The software offers many versatile and flexible solutions needed to study the patient 3D model.

\section{Material and methods}

The data from AAOP file are transcribed on an Excel spreadsheet. The cylindrical coordinates are transformed into Cartesian coordinates $(\mathrm{X}, \mathrm{Y}, \mathrm{Z})$. The model is viewed through two graphs, one reproducing the $3 \mathrm{D}$ model and the other to view points of a selected horizontal section. Each horizontal plane contains 90 points. We create a fourth axis $Y^{\prime}$ with the same origin than $\mathrm{Y}$, but defining with $\mathrm{Y}$ a variable and controlled alpha angle by a counter "alpha position". The coordinates of points according to this new axis are determined by: $Y^{\prime} \mathrm{p}=\mathrm{Yp} \cos (\mathrm{alpha})+\mathrm{Zp} \sin ($ alpha) .

Clinique du Parc, Lyon, France

Full list of author information is available at the end of the article
Looking back along the modification of the angle between $\mathrm{X}$ axis and the tangent at the spinous process level, we visualize the rotation of the spine. Arbitrarily, the calculation of the tangent is made around the $45^{\circ}$ point of each horizontal plan $\left(180^{\circ}\right)$ using the coordinates point 43 and point 47. Figure 1 .

The two files before and after plaster cast are open on the same worksheet, which facilitates comparison. The reference plane is at the sacrum level.

\section{Results}

We studied 100 files before and after the initial plaster cast, comparing the gamma angle with the Bunnel ATR angle.

Qualitatively, there is a correlation between the location of the scoliosis and the visual chart. Similarly changes between the two images are proportional to the rigidity of the curve.

We have no correlation between the value of the gamma angle and the Bunnell ATR.

\section{Discussion}

The Orten system is an orthotics dedicated device for custom made orthosis. It can be used as a tool for measuring the asymmetry of the trunk, but the results are not comparable to that obtained by the ATR in forward bending.

\section{Conclusion}

In this work, the gamma angle and its change after plaster cast is a new objective entity which still requires much research to be used in daily practice. 


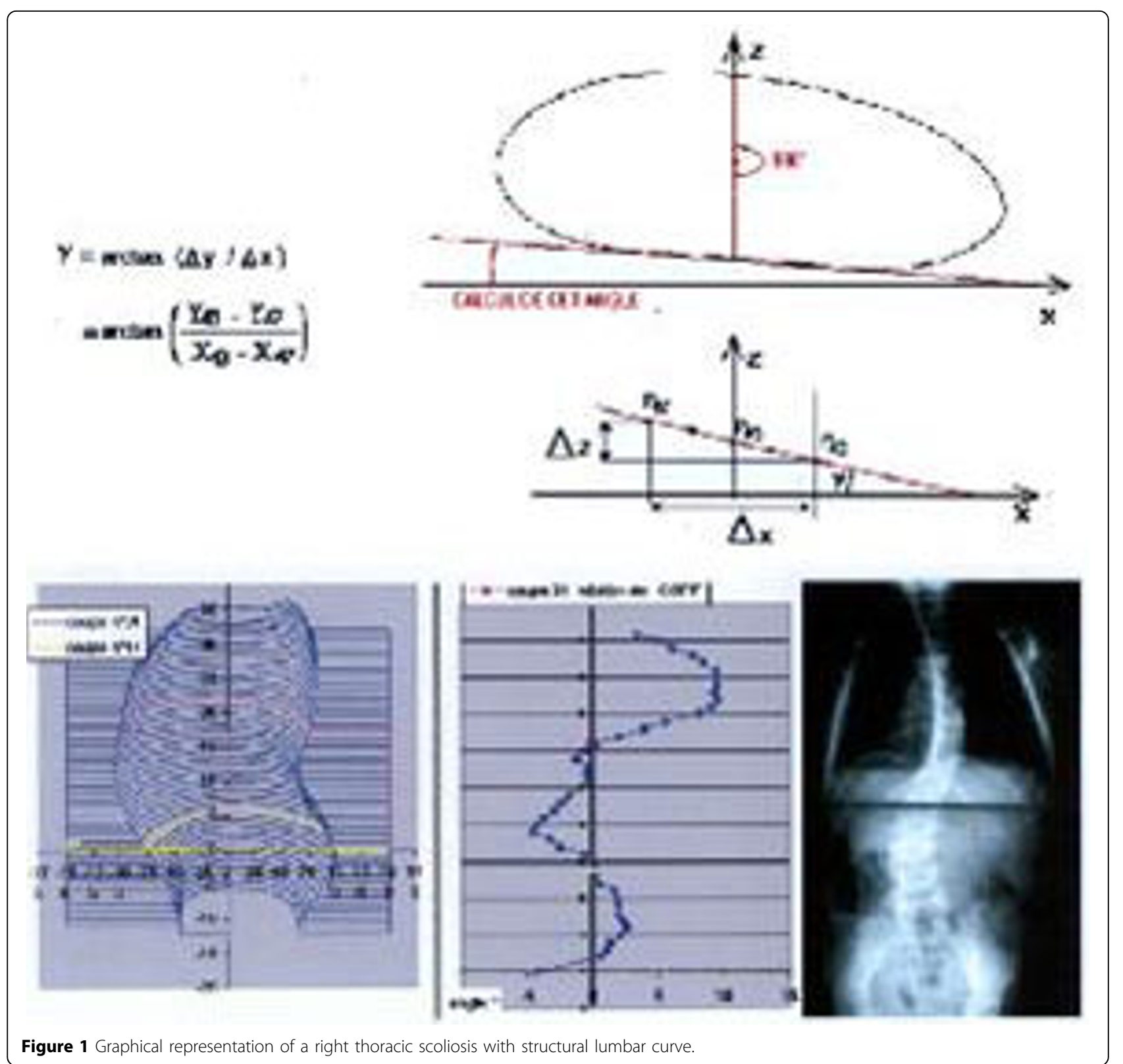

Published: 10 September 2010

\section{Reference}

1. Sciandra Jean, deMauroy Jean Claude, Rolet Guy, Kohler Rémi, Creach Jean Pierre: Accurate and fast non-contact 3D acquisition of the whole trunk. Three-dimensional analysis of spinal deformities Amsterdam, NL, Technology and Informatics 15. Oxford IOS PressD'Amico M 1995, 81-85.

doi:10.1186/1748-7161-5-S1-013

Cite this article as: de Mauroy et al:: Developing a tool to measure objectively the rib hump from an instantaneous 3D scanning in a full upright position. Results of 50 scoliosis before and after plaster cas. Scoliosis 2010 5(Suppl 1):013.

\section{Submit your next manuscript to BioMed Central} and take full advantage of:

- Convenient online submission

- Thorough peer review

- No space constraints or color figure charges

- Immediate publication on acceptance

- Inclusion in PubMed, CAS, Scopus and Google Scholar

- Research which is freely available for redistribution

Submit your manuscript at www.biomedcentral.com/submit 